\title{
A controlled trial of glycopyrronium and 1-hyoscyamine in the long-term treatment of duodenal ulcer
}

Michael D. KAYE, J. RHODES, PETER BECK, PETER M. SWEETNAM, G. T. DAVIES, AND K. T. EVANS

From the Department of Medicine and Radiology, Royal Infirmary, Cardiff, and the MRC Epidemiological Research Unit, Cardiff

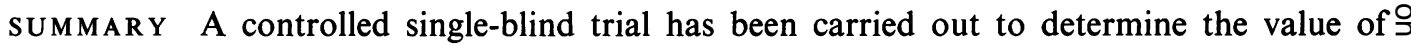
long-term anticholinergic therapy in duodenal ulcer. Of 106 male patients with symptomatic $\vec{c}$ and radiologically proven duodenal ulcer admitted to the trial, 91 completed the study. Patients were divided randomly into three groups. They received either glycopyrronium, or $\vec{v}$ l-hyoscyamine in a sustained-release form, or inert tablets for one year.

Progress was judged on the basis of frequency and severity of symptoms, monthly assessments by patients, antacid consumption, and radiology. By all criteria, glycopyrronium and 1-hyoscyamine were not significantly superior to placebo.

Symptomatic improvement, both subjective and objective, occurred in approximately $80 \%$ of all patients during the year of observation; there was no significant difference between the groups.

Because anticholinergic agents reduce gastric motility and acid secretion, they have been used extensively in the treatment of peptic ulcer. In Britain the annual expenditure on such drugs is about two million pounds. Their value, however, in clinical practice is disputed and conclusions from clinical trials, many of which were uncontrolled, are conflicting.

We have attempted in this study to assess the value of two anticholinergic drugs-one a natural alkaloid, the other a synthetic compound-in the long-term treatment of patients with duodenal ulceration.

\section{Method}

\section{PATIENTS}

One hundred and six male patients (aged between 20 and 65) were admitted to the trial. They had had symptoms of peptic ulcer during the previous six months, and had had an ulcerated and/or deformed duodenal cap demonstrated by radiology.

At the first interview, the nature and purpose of the trial were explained, and a standard quesReceived for publication 10 December 1969. tionnaire relating to the clinical history was completed. Those who agreed to take part in the trial and in whom there was no evidence of 3 . ischaemic heart disease, prostatic obstruction, $\delta$ glaucoma, or any serious disease which might $₹$ have prejudiced their completion of the trial, $ᄋ$ commenced a 'run-in' period. During this time, which varied from two to six weeks, the subjects received inert tablets three times daily and antacid tablets for relief of discomfort. They were $\%$ asked to record daily on a standard diary card $N$ (Fig. 1) the occurrence during the day of dis- $N$ comfort, graded in severity from $0-3$; night pain; and vomiting. Those who failed to complete the 'run-in' period satisfactorily were excluded.

TRIAL DESIGN

The active preparations were given in doses which $\overparen{D}$ produced tolerable side effects. The nature of $\overrightarrow{\mathbb{D}}$ treatment was therefore known to the 'doctor, $\sigma$ but not to the patient. The trial period for each patient was one year.

Patients were allocated randomly by a system of cards in numbered envelopes, to one of three groups. Group A were given glycopyrronium ${ }^{1} a$ ${ }^{1}$ Robinul, A. H. Robins Co. Ltd. 
INSTRUCTIONS TO PATIENT

Pain by day
Each day select the statement which most nearly describes the sort of
day you have had and mark the number in the day column.
0. I have had no discinffort to-day.
I. I have had slight disconfort at some time to-day.
2. I have had severe disconfort at some time to-day.
3. I have had severe discomfort for most of to-day.
IDiscomfort means your complaint. whether it he pain. indigestion.
distention. flatulence, soreness, nauseat or heartburn).
Pain at night
Each night select the appropriate statement and mark the number in
the night column.
0. Last night I did not wake with pain.
1. Last night I awoke with pain.
Vomiting (mark number in appropriate column)
(). I have not vomited in the last 24 hours.
I. I have vomited in the last 24 hours.

\begin{tabular}{|c|c|c|c|c|c|}
\hline DAY & $\begin{array}{l}\text { DISCOMFORT } \\
\text { day | night } \\
\end{array}$ & vomiting & DAY & $\begin{array}{l}\text { DISCOMFORT } \\
\text { day night }\end{array}$ & vomiting \\
\hline 1 & & & 15 & & \\
\hline 2 & & & 16 & & \\
\hline 3 & & & 17 & & \\
\hline 4 & & & 18 & & \\
\hline 5 & & & 19 & & \\
\hline 6 & & & 20 & & \\
\hline 7 & & & 21 & & \\
\hline 8 & & & 22 & & \\
\hline 9 & & & 23 & & \\
\hline 10 & & & 24 & & \\
\hline 11 & & & 25 & & \\
\hline 12 & & & 26 & & \\
\hline 13 & & & 27. & & \\
\hline 14 & & & 28 & & \\
\hline
\end{tabular}

Fig. 1 Diary card used to record symptoms during the trial.

quaternary ammonium compound which is slowly absorbed and long-acting. Group $\mathbf{B}$ received 1-hyoscyamine ${ }^{1}$. This natural alkaloid of belladonna is slowly released from a plastic matrix and therefore has a prolonged action. Group C received inert tablets which were identical in appearance to those given to groups $\mathbf{A}$ and $\mathbf{B}$.

Tablets were taken three times daily by all patients. In groups A and B, dosage was adjusted so that tolerable side effects were experienced. Dosage in group $\mathrm{C}$ was altered arbitrarily according to symptoms and complaint of side effects. All patients were advised to avoid articles of diet which they knew might precipitate their ulcer discomfort, to restrict consumption of alcohol and tobacco, and to avoid aspirin-containing preparations.

\section{ASSESSMENT}

Three independent methods of assessment were used.

${ }^{1}$ Egacen durules, Astra Ltd, Sweden.

\section{Symptoms}

Throughout the trial, patients recorded each day, on the standard diary card (Fig. 1), the occurrence of discomfort during the day, graded in severity from 0 (no discomfort) to 3 (severe pain most of the day), night pain, and vomiting. They were seen by one of three observers (M.K., J.R., P.B.) at four-weekly intervals at a special clinic. In addition a standard questionnaire was completed at each interview. The patient graded his ulcer symptoms for the previous four weeks as 'excellent', 'good', 'fair', 'bad', or 'terrible'. At the end of the trial the patient was asked, 'As far as your ulcer trouble is concerned, have you, during the last year, been better, worse, or the same, in comparison with the year immediately before you started coming to the clinic?'

\section{Antacid consumption}

All patients were given a standard antacid tablet ${ }^{2}$, and advised to take this for relief of discomfort. The number consumed each month was recorded and provided an objective index of symptoms.

\section{Radiology}

A barium meal was performed on each patient before admission to, and again at the end of, the trial. Abnormalities in the first and second parts of the duodenum were assessed and recorded independently by two radiologists (K.T.E. and G.T.D.) under the headings 'crater', 'deformity', and 'coarse folds'. Patients were included in the trial only if both radiologists recorded the presence of a crater and/or a deformity. Those with evidence of oesophageal disease, hiatus hernia, gastric ulcer, or gastric outlet obstruction, were excluded.

\section{ACID SECRETION}

Basal and maximal acid output were measured before admission to the trial and again one year later, seven days after cessation of drug administration. After a fast of at least 12 hours, basal secretion was collected for 30 minutes. A constantrate intravenous infusion of pentagastrin ${ }^{3}, 6 \mu \mathrm{g} /$ $\mathrm{kg} / \mathrm{hr}$, was then given for 75 minutes and secretion collected as five 15-minute samples. Maximal acid output, expressed in m-equiv/hr, was calculated from the last three or four samples.

\section{SIDE EFFECTS}

At each clinic visit, patients were asked a standard series of questions concerning side effects referable to mouth, eyes, bladder, bowel, and heartbeat.

\footnotetext{
'Actal, Bayer.
}

septavlon, ICI. 
FOLLOW UP

If a patient failed to attend, a new diary card and a further appointment for the next available clinic were immediately sent to him. If this second appointment was not kept, he was visited in his home by one of us (M.K., J.R., P.B.).

\section{STATISTICAL METHODS}

Wherever possible, comparisons between groups have been based upon standard statistical techniques (Student's $t$ test, $\chi^{2}$ test, and analysis of variance). However, the distributions of the score

\begin{tabular}{|c|c|c|}
\hline Patient & Group & Reason for Withdrawal from Trial \\
\hline WG & $\mathbf{A}$ & $\begin{array}{l}\text { Bronchitic symptoms exacerbated by anti- } \\
\text { cholinergic therapy }\end{array}$ \\
\hline JM & $\mathbf{A}$ & Moved from district \\
\hline DP & $\mathbf{A}$ & Moved from district \\
\hline JW & $\mathbf{A}$ & Sent to prison \\
\hline BB & $\mathbf{A}$ & Referred for surgery \\
\hline CJ & $\mathbf{A}$ & Withdrawn following myocardial infarction \\
\hline DT & $\mathbf{A}$ & Persistent failure to attend \\
\hline EJ & B & Persistent failure to attend \\
\hline SF & $\mathbf{B}$ & Persistent failure to attend \\
\hline DM & $\overline{\mathbf{B}}$ & At request of patient \\
\hline LW & $\mathbf{B}$ & At request of patient \\
\hline M O'R & $\mathbf{B}$ & Moved from district \\
\hline DC & $\mathbf{C}$ & Moved from district \\
\hline $\mathbf{R H}$ & C & At request of patient \\
\hline RT & C & At request of patient \\
\hline
\end{tabular}

Table I Reasons for withdrawal from the trial in the 15 patients failing to complete the full period of assessment

\begin{tabular}{|c|c|c|c|}
\hline \multirow[t]{2}{*}{ Group } & \multirow{2}{*}{$\begin{array}{l}\text { No. of } \\
\text { Subjects }\end{array}$} & \multicolumn{2}{|c|}{ No. of Tablets per Day } \\
\hline & & $M_{e a n^{1}}$ & Range \\
\hline $\begin{array}{l}\text { A (glycopyrronium) } \\
\text { B (l-hyoscyamine) } \\
\text { C (placebo) }\end{array}$ & $\begin{array}{l}28 \\
31 \\
32\end{array}$ & $\begin{array}{l}5 \cdot 1^{2} \\
5 \cdot 8^{2} \\
6 \cdot 3\end{array}$ & $\begin{array}{l}1-11 \\
2-15 \\
1-15\end{array}$ \\
\hline
\end{tabular}

Table II Drug dosage during the trial

'The overall mean values shown are derived from the sum of the individual means.

${ }^{2}$ Tablet strength was $1 \mathrm{mg}$ for glycopyrronium, and $\mathbf{0 . 2} \mathrm{mg}$ for 1-hyoscyamine. for daytime pain, night pain, vomiting, and antacid consumption are all very positively skewed. Since Student's t test and the analysis of variance technique cannot properly be applied to such data, we have used instead the corresponding 'distribution-free' tests, namely, the Wilcoxon (Mann-Whitney) and the KruskalWallis one-way analysis of variance. The association between scores for different symptoms has been assessed by the Spearman rank correlation coefficient.

\section{Results}

One hundred and six patients were admitted to the trial; 91 completed the full period of assessment. Details of the 15 patients who were withdrawn from the trial are given in Table I. Subsequent remarks are confined to the 91 who completed the trial. Of these, 28 were in group $\mathrm{A}$ (glycopyrronium), 31 in group B (1-hyoscyamine), and 32 in group $C$ (placebo). The number of tablets taken is shown in Table II.

Randomization was checked in respect of age, duration of symptoms, nature of symptoms, previous complications, smoking habits, initial maximal acid output, radiological presence or absence of craters at the beginning of the trial, and social class (Table III). The three groups were similar except that the incidence of night pain in patients from group A (glycopyrronium) was significantly lower $(P<0.01)$ than in the other two groups. For this reason patients with, and without, a previous history of night pain were analysed separately. The seven patients in group B who had no history of night pain fared significantly better than comparable members of the other two treatment groups in some, although not all, respects. Total day pain and antacid consumption were more favourable $(\mathrm{P}<0.01)$ than in the other two groups and monthly measurements were more favourable than in the placebo group.

\begin{tabular}{|c|c|c|c|c|}
\hline & \multicolumn{3}{|l|}{ Group } & \multirow{2}{*}{$\begin{array}{l}\text { Significance of Differences } \\
\text { between Groups }\end{array}$} \\
\hline & $A$ (Glycopyrronium) & B (1-Hyoscyamine) & $C($ Placebo $)$ & \\
\hline $\begin{array}{l}\text { Age } \\
\text { Duration of symptoms (years) } \\
\text { History of previous night pain } \\
\text { History of previous vomiting } \\
\text { Previous complications (perforation or }\end{array}$ & $\begin{array}{l}39 \pm 9 \\
10 \cdot 6 \pm 9 \cdot 7 \\
11 \\
9\end{array}$ & $\begin{array}{l}41 \pm 9 \\
8 \cdot 4 \pm 7 \cdot 0 \\
24 \\
13\end{array}$ & $\begin{array}{l}39 \pm 12 \\
6 \cdot 4 \pm 5 \cdot 5 \\
21 \\
20\end{array}$ & $\begin{array}{l}\text { Not significant } \\
\text { Not significant } \\
P<0.01 \\
\text { Not significant }\end{array}$ \\
\hline $\begin{array}{l}\text { haemorrhage) } \\
\text { Cigarette consumption (no./day) } \\
\text { Presence of crater on initial radiograph }\end{array}$ & $11 \pm 10$ & ${ }^{7}+12$ & $13 \pm 10$ & $\begin{array}{l}\text { Not significant } \\
\text { Not significant }\end{array}$ \\
\hline $\begin{array}{l}\text { Definite } \\
\text { Possible } \\
\text { Initial maximal acid output (m-equiv/hr) }\end{array}$ & $\begin{array}{l}7 \\
8 \\
39 \cdot 6 \pm 9 \cdot 0\end{array}$ & $\begin{array}{l}10 \\
6 \\
41 \cdot 6 \pm 11 \cdot 8\end{array}$ & $\begin{array}{l}5 \\
9 \\
39 \cdot 1 \pm 10 \cdot 1\end{array}$ & $\begin{array}{l}\text { Not significant } \\
\text { Not significant } \\
\text { Not significant }\end{array}$ \\
\hline
\end{tabular}

Table III Details of check on randomization ${ }^{1}$

${ }^{1}$ Figures shown are means \pm 1 SD. There was no significant difference between groups in respect of social class, which is not included here. 


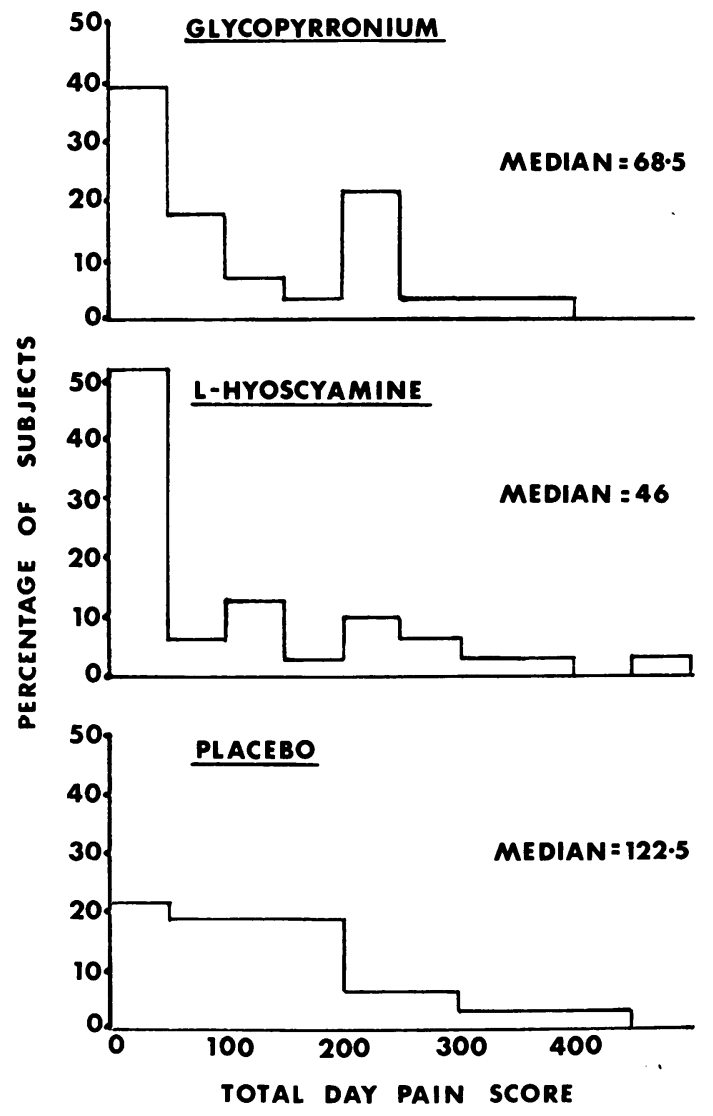

Fig. 2 Day pain scores during the trial. For each patient the total score was calculated by adding all daily scores for the year.

EFFECT OF TREATMENT ON SYMPTOMS

Day pain, night pain, and vomiting

Day pain was recorded daily by all subjects as $0 \stackrel{?}{?}$ (no discomfort), 1 (slight discomfort), 2 (severe $\vec{F}$ discomfort for part of the day), or 3 (severe discomfort for most of the day), and a total score was calculated for each patient by simple addition of all daily scores for the year (Fig. 2). There was no significant difference between the three groups. Furthermore, the distributions for the o total number of days on which each of the four $\overrightarrow{0}$ grades (0-3) of discomfort occurred were similar for the three groups. There was no significant difference between the groups either in the total $\widehat{Q}$ number of nights of pain experienced during the trial (Fig. 3) or in the total number of days on which vomiting occurred (Fig. 4).

\section{Monthly assessments}

At each four-weekly visit, patients were asked which of the five terms, 'excellent', 'good', 'fair', 'bad', or 'terrible' most nearly described their symptoms of the previous four weeks. These answers were graded from 1 ('excellent') to 5 ('terrible'). Thus, the range of total scores for the year for each patient was from 13 to 65 . The distribution of the total scores for the year were similar in the three groups (Fig. 5).

Final assessments

At the end of the trial approximately $80 \%$ in each $\overrightarrow{\vec{O}}$ group felt that they had been better. Direct comparison was also made in each patient between the first three and the last three months of the trial, ignoring the intervening six months. A majority of patients in each group had a lower score during the last three months of the trial (Table IV) and there was no difference between the groups (analysis of variance). This would indicate that neither glycopyrronium nor l-hyoscyamine produced a significant reduction in symptoms as compared with placebo.
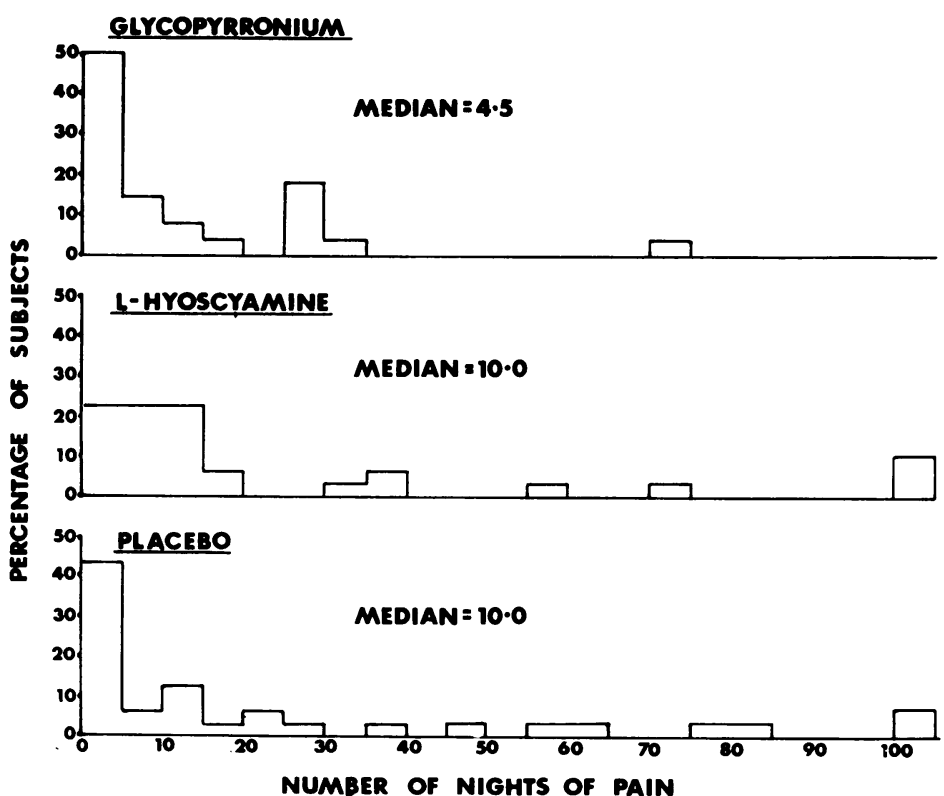

\begin{tabular}{lllc}
\hline Group & $\begin{array}{l}\text { No. of } \\
\text { Subjects }\end{array}$ & Better & Unchanged or Worse \\
\hline A (Glycopyrronium) & 28 & $22(79)$ & $6(21)$ \\
B (l-hyoscyamine) & 31 & $20(65)$ & $11(35)$ \\
C (placebo) & 32 & $23(72)$ & $9(28)$ \\
Total & $91(100)$ & $65(71)$ & $26(29)$ \\
\hline
\end{tabular}

Table IV Evidence for symptomatic improvement during the trial, based upon a comparison between symptom scores for the first three months, and the last three months, of the trial ${ }^{2}$

${ }^{1}$ Figures in brackets indicate percentages. For difference between groups, $\chi^{2}(\mathrm{df})=1 \cdot 4, \mathrm{P} \bumpeq 0.5$

Fig. 3 Number of nights on which pain occurred during the trial.
ANTACID CONSUMPTION
Almost all patients found that Actal relieved their ulcer discomfort. There was no significant differ- 


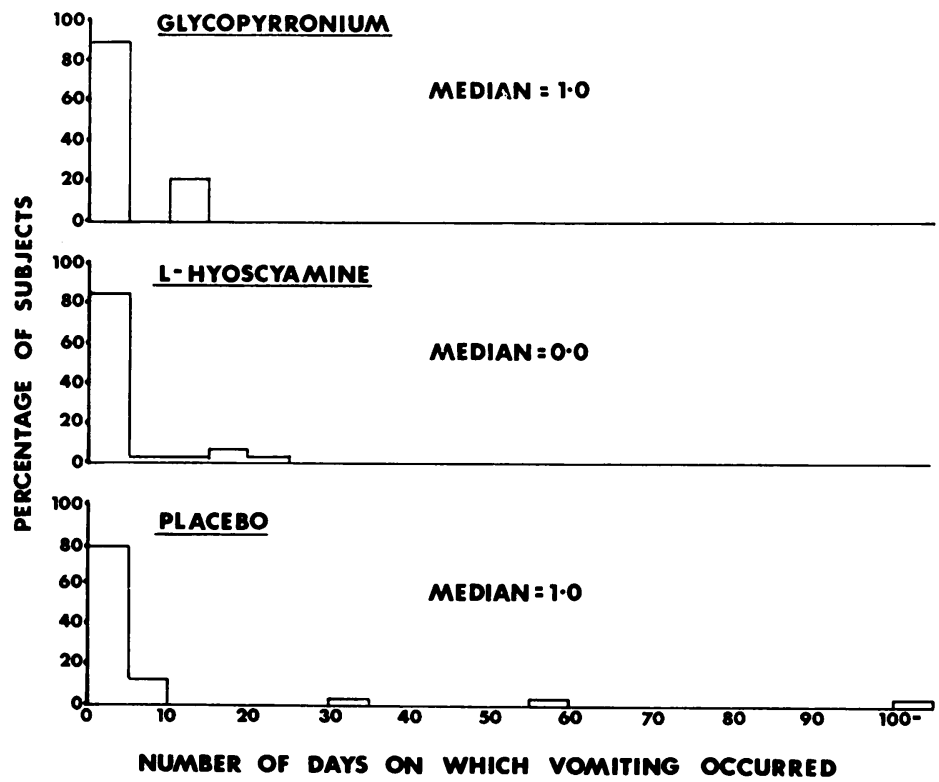

Fig. 4 Number of days on which vomiting occurred during the trial.

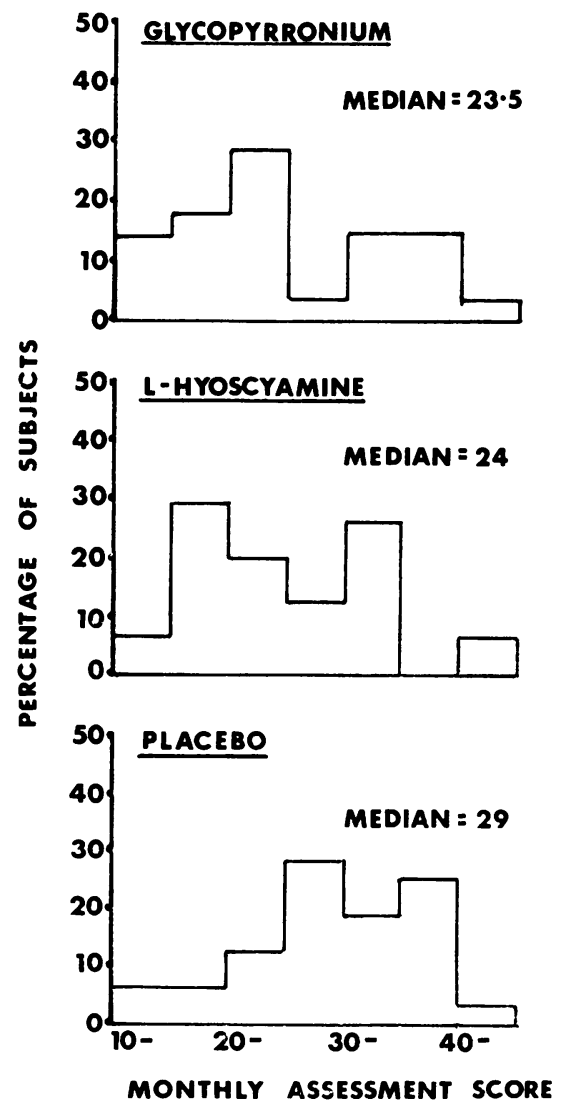

Fig. 5 Monthly assessment scores during the trial. The total score for each patient was calculated by addition of his 13 monthly scores, which for cny month ranged from 1 ('excellent') to 5 ('terrible').

\begin{tabular}{lllll}
\hline & \multicolumn{2}{l}{ Pain } & Vomiting & $\begin{array}{l}\text { Antacid } \\
\text { Consumption }\end{array}$ \\
\cline { 2 - 2 } & Day & Night & & \\
\hline Night pain & 0.447 & & & \\
Vomiting & 0.352 & 0.515 & & \\
Antacid consumption & 0.793 & 0.583 & 0.439 & \\
Monthly assessment & 0.837 & 0.466 & 0.404 & 0.742 \\
\hline
\end{tabular}

Table $\mathrm{V}$ Correlation between symptoms as recorded on diary cards, antacid consumption, and monthly assessments, for all patients (Spearman rank correlation coefficients $)^{1}$

${ }^{1}$ All coefficients are significan:ly differcnt from zero $(P<0.001)$

ence between groups in respect of antacid consumption (Fig. 6).

Correlations between Methods of Symptom Assessment

Comparison of the various methods of assessment used are shown in Table V. Since correla- $\vec{\omega}$ tions between symptoms were very similar in the three groups, only the coefficients (Spearman rank correlation) for all groups combined are shown. All coefficients are significantly different ( $P<0.001)$ from zero, those between day pain, monthly assessments, and antacid consumption being particularly high.

\section{RADIOLOGY}

For the purposes of analysis, each sign (crater, deformity, and coarse folds) was scored as 2 when both radiologists were agreed on its presence, 0 when they were agreed on its absence, and 1 when there was disagreement. Analysis of variance revealed no significant difference between the groups in respect of any of these signs (Table VI). In all groups craters tended to disappear, while, with a few exceptions, deformity and coarse folds changed little.

\section{ACID SECRETION}

Basal and maximal acid output at the beginning and end of the trial are shown in Table VII. During the year, basal acid output remained un- $?$ changed in group C (placebo), increased, but not significantly, in group B (l-hyoscyamine), and increased significantly $(P<0.05)$ in group $A$ (glycopyrronium). There was no significant change in maximal acid output in any of the groups. These findings have been reported in detail elsewhere (Kaye, Beck, Rhodes, and 8 Sweetnam, 1969). There was no correlation betwcen the symptom scores for either day pain or night pain with the basal or maximal acid secretion. 
GLYCOPYRRONIUM $(n=27)$
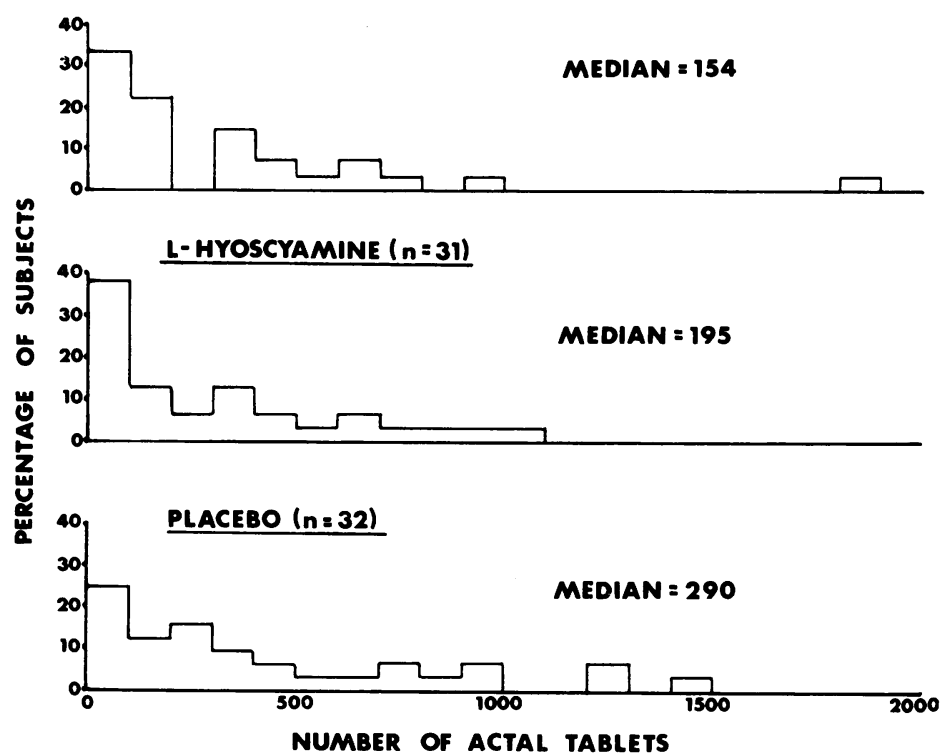

SIDE EFFECTS

In the dosages used, both drugs produced significant dryness of the mouth and blurring of vision but neither drug significantly affected micturi- $\Omega$ tion or heart beat. There was a suggestion $?$ $(\mathrm{P}<0 \cdot 1)$ that more patients on glycopyrronium $\overrightarrow{\vec{F}}$ suffered from constipation, but otherwise the side effects were similar with the two anticholinergic drugs.

Loss of libido was a common complaint, but sexual performance was not adversely affected by either glycopyrronium or l-hyoscyamine.

\section{COMPLICATIONS}

The only complication occurred in one patient $\overparen{C}$ from group B (1-hyoscyamine) who developed melaena three days before he completed the trial. Surgery was performed shortly after the trial in four patients with severe symptoms. Two of these were from group A (glycopyrronium) and two from group $\mathrm{C}$ (placebo).

\section{Discussion}

Fig. 6 Antacid consumption during the trial.

\begin{tabular}{llll}
\hline Group & Crater & Scar & $\frac{\text { Coarse Folds }}{\text { First Part }}$ \\
& Initial Final & Initial Final & Initial Final Initial Final \\
\hline
\end{tabular}

A (glycopyrronium)

Present

Possible

$\begin{array}{rrrr}7 & 3 & 24 & 22 \\ 8 & 3 & 2 & 3\end{array}$

1
4

Absent

Present

Possible

Absent

C (placebo)

Present

Possible

Absent

$\begin{array}{rr}8 & 22\end{array}$

2

23

$\begin{array}{rr}2 & 5 \\ 11 & 2\end{array}$

528

$\begin{array}{rrrr}10 & 3 & 29 & 27 \\ 6 & 4 & 1 & 1\end{array}$

4
4
23

$\begin{array}{rr}3 & 8 \\ 4 & 5 \\ 24 & 18\end{array}$

9

$\begin{array}{rrrr}5 & 4 & 29 & 30 \\ 9 & 1 & 3 & 0\end{array}$

2
6
24

$\begin{array}{rrr}7 & 7 & 9 \\ 4 & 6 & 5 \\ 21 & 19 & 18\end{array}$

Table VI Radiological abnormalities in duodenum at beginning and end of trial

${ }^{1}$ Any sign which was recorded as 'present' by one radiologist, but 'absent' by the other, is included in 'possible.

\begin{tabular}{lllllll}
\hline Group & \multirow{2}{*}{$\begin{array}{l}\text { No. of } \\
\text { Subjects }\end{array}$} & \multicolumn{2}{l}{ Basal Acid Output } & & \multicolumn{2}{c}{ Maximal Acid Output } \\
\cline { 3 - 3 } & & Initial & Final & & Initial & Final \\
\hline A (glycopyrronium) & 28 & $5 \cdot 0 \pm 4 \cdot 4$ & $8 \cdot 2 \pm 5 \cdot 7$ & & $39 \cdot 6 \pm 9 \cdot 8$ & $36 \cdot 3 \pm 14 \cdot 0$ \\
B (l-hyoscyamine) & 30 & $6 \cdot 7 \pm 5 \cdot 7$ & $8 \cdot 3 \pm 4 \cdot 9$ & & $41 \cdot 6 \pm 11 \cdot 8$ & $41 \cdot 1 \pm 12 \cdot 2$ \\
C (placebo) & 32 & $6.9 \pm 8 \cdot 4$ & $7 \cdot 0 \pm 6 \cdot 1$ & & $39 \cdot 1 \pm 10 \cdot 1$ & $39 \cdot 2 \pm 10 \cdot 7$ \\
\hline
\end{tabular}

Table VII Changes in basal and maximal acid output ${ }^{1}$ ${ }^{1}$ Results are expressed in m-equiv/hr (mean $\pm 1 \mathrm{SD}$ ).
Relatively few controlled clinical studies of the effect of anticholinergic drugs in peptic ulcer have been carried out. Various trial designs have been used, various criteria for assessment selected, and discrepant conclusions reached.

Friedlander (1954), in a controlled trial in patients with duodenal ulcer, found that methantheline produced initial symptomatic benefit compared with a placebo, but this was not maintained. Later Ruffin and Cayer (1962), in a large double-blind study involving 1,034 patients with peptic ulcer, found that $48 \%$ of patients on placebo, $53 \%$ of those on atropine, and $74 \%$ of those on synthetic anticholinergics improved. No ability of groups. A similar criticism applies to the trials described by Sun (1962), who assessed progress on the basis of recurrences, the latter being defined as 'ulcer-like symptoms with or without crater, deformity, irritability of duodenum, or ... painless bleeding'. Six of 20 patients in the placebo group bled, as opposed to one of 25 patients given tricycamol. The overall recurrence rates were $45 \%$ and $8 \%$ respectively, a significant difference. In a later trial (Sun, 1964), glycopyrronium was used, and it was found that ulcer-like symptoms recurred in $15 \%$ of patients on glycopyrronium, but, on this occasion, in $71 \%$ of those on placebo. A further trial comparing glycopyrronium and placebo in duodenal ulcer was carried out by Trevino, Anderson, Davey, and Henley (1967). Forty-six patients with proven duodenal ulcer were followed for between 18 and 27 months and glycopyrronium was not significantly superior to the placebo.

Poldine methosulphate ${ }^{1}$, an anticholinergic ${ }^{1}$ Nacton, Bencard. information, however, is given on the compar- 
agent which, like glycopyrronium, has a quaternary ammonium structure, was not found to be superior to a placebo when given for nine months to patients with duodenal ulcer (Melrose and Pinkerton, 1961). Lennard-Jones (1961) came to the same conclusion in a single-blind crossover study of 11 patients, all of whom were followed for two consecutive three-month periods. Similarly Hunt and Wales (1966) in a long-term study of 15 patients with peptic ulcer were unable to show that the course of the disease was significantly affected by poldine, although acid secretion was reduced for many months after drug withdrawal.

The course of untreated duodenal ulcer is one of recurrence and remission, and objective evaluation is difficult. Sequential radiological examinations are of little value in assessing activity in chronic duodenal ulcer. A deformed duodenal cap may be due to fibrosis, or coarse duodenal folds, and, in either case, there may be doubt about the presence of an ulcer crater. In this trial there were no significant differences between groups in respect of any of the radiological signs. In those considered to have ulcer craters at the initial examination, healing occurred with similar frequency in the three groups.

Loss of working time has also been used as an index of progress (Lennard-Jones, 1961; Hunt and Wales, 1966). We abandoned this criterion when we found that the reasons for loss of work could not be assessed; several patients were unemployed throughout the trial.

Complication rate provides an objective guide to the course of duodenal ulcer (Sun, 1962 and 1964) but in our series of 91 patients followed for a year, only one complication occurred and the number who required surgery was too small to justify any comparison between the groups. These results are in marked contrast to those of Sun, and may reflect differences in the populations of patients studied.

For these reasons our assessment was based entirely upon an objective analysis of symptoms. The high degree of correlation between antacid consumption, monthly assessments, and symptom score (from diary cards) supports the validity of our method of assessment.

A double-blind trial was considered to be impracticable because the active drugs were given in maximum tolerable doses. In retrospect, a crossover trial might have been preferable. Such a design was not chosen because of the report (Hunt and Wales, 1966) that prolonged continuous administration of poldine to patients with peptic ulcer reduced acid secretion for considerable periods after drug withdrawal. In fact, there was no evidence in our patients that basal or maximal acid output were reduced beyond the period of drug administration though both drugs used in this trial have been shown to inhibit gastric acid secretion as provoked by a variety of stimuli (Moeller, 1962; Posey, 1962;
Sun, 1962; Abbott, Sourial, Krieger, and Levey, 1962; Barman and Larson, 1963; Dotevall, Schröder, and Walan, 1965; Christianson and Rodbro, 1967; Kaye, Rhodes, and Sweetnam, $?$ 1968). Indeed, basal output, measured seven days $\rightleftharpoons$ after treatment was stopped, was increased in $\overrightarrow{\vec{F}}$ patients who had received anticholinergic drugs, significantly so in those given glycopyrronium. 당 It is possible that this increase was transient, and $\frac{\bar{F}}{\bar{c}}$. in the nature of a 'rebound' phenomenon but $\widehat{\bar{\alpha}}$ since further secretory studies were not done this is speculative.

Although differences between the three groups $\overrightarrow{0}$ were statistically insignificant, the median values $\overrightarrow{-}$ for all methods of symptom assessment suggest ${ }_{\sigma}$ that patients given glycopyrronium or 1-hyo-e scyamine fared slightly better than those who received placebo. It seems likely, however, that $\overrightarrow{-}$ this small difference is clinically unimportant. In view of the side effects of these drugs, we would जु conclude that their long-term prophylactic use $e_{0}$ in patients with duodenal ulcer is not justified.

That a substantial proportion of patients in this $\vec{C}$ trial showed both subjective and objective evidence of improvement during the year of $\vec{\varphi}$ observation is not altogether unexpected. If it is true that around $10 \%$ of the population are at. some time of their lives afflicted by duodenal ulcer (Watkinson, 1960) then it seems likely that relatively few suffer severely for a long time, develop complications, or require surgery. The need for adequate controls in trials of any form of treat- $\stackrel{\Phi}{2}$ ment for this condition cannot be over- $\overrightarrow{\vec{O}}$ emphasized.

Drugs were generously supplied by Astra (Sweden) Ltd, Bayer Products Co, Imperial Chemical Industries Ltd, and A. H. Robins Co, Ltd.

We are grateful to Professor A. L. Cochrane, Dr J. Ingham and Dr J. Lennard-Jones for help in the design of the trial; to Mrs Valerie Jenkins $\frac{7}{0}$ and Miss Jane Richards for invaluable secretarial assistance; to Professor H. Scarborough for $\mathcal{N}$ criticism of the manuscript; to $\mathrm{Mr}$ Ralph N Marshall, Department of Medical Illustration, N Cardiff Royal Infirmary, for the figures, and to medical colleagues, for referring patients.

Dr J. Rhodes was in receipt of an MRC grant $\stackrel{\bullet}{=}$ during part of this study.

\section{References}

Abbott, W. E., Sourial, A. S., Krieger, H., and Levey, S. (1962). Effect of glycopyrrolate (Robanul) on basal and histamineor insulin-induced gastric secretion. Ann. N.Y. Acad. Sci.,

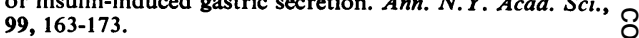

Barman, M. L., and Larson, R. K. (1963). The effect of glyco- 은 pyrrolate on nocturnal gastric secretion in peptic ulcer patients. Amer. J. med. Sci., 246, 325-328.

Christiansen, P. M., and Rodbro, P. (1967). Gastric secretory patterns before and during treatment with 1-hyoscyamine. Scand. J. Gastroent., 2, 251-256. 
Dotevall, G., Schröder, G., and Walan, A. (1965). The effect of poldine, glycopyrrolate and 1-hyoscyamine on gastric secretion of acid in man. Acta med. scand., 177, 169-174.

Friedlander, P. H. (1954). Ambulatory treatment of duodenal ulcers; effects of fruit juice, olive oil, hexamethonium and methantheline. Lancet, 1, 386-390.

Hunt, J. N., and Wales, R. C. (1966). Progress in patients with peptic ulceration treated for more than five years with poldine, including a double-blind study. Brit. med. J., 2, 13-16.

Kaye, M. D., Beck, P., Rhodes, J., and Sweetnam, P. M. (1969). Gastric acid secretion in patients with duodenal ulcer treated for one year with anticholinergic drugs. Gut, 10 774-778.

Kaye, M. D., Rhodes, J., and Sweetnam, P. M. (1968). Clinical evaluation of three long-acting anticholinergic compounds. Gut, 9, 590-596.

Lennard-Jones, J. E. (1961). Experimental and clinical observations on poldine in treatment of duodenal ulcer. Brit. med. J., 1, 1071-1076.

Melrose, A. G., and Pinkerton, I. W. (1961). Clinical evaluation of poldine methosulphate. Brit. med. J., 1, 1076-1078.
Moeller, H. C. (1962). Physiological effects and clinical evaluation of glycopyrrolate in peptic ulcer disease. Ann. N.Y. Acad. Sci., 99, 158-162.

Posey, E. L. (1962). Management of peptic ulcer with glycopyrrolate. Amer. J. dig. Dis., 7, 863-872.

Ruffin, J. M., and Cayer, D. (1962). The role of anticholinergic drugs in treatment of peptic ulcer disease. Ann. N.Y. Acad. Sci., 99, 179-189.

Sun, D. C. H. (1962a). The medical management of duodenal ulcer and long term study with drug therapy in the prevention of recurrences. Ann. N.Y. Acad. Sci., 99, 104-113.

Sun, D. C. H. (1962b). Comparative study on the effect of glycopyrrolate and propantheline on basal gastric secretion. Ann. N.Y. Acad. Sci., 99, 153-157.

Sun, D. C. H. (1964). Long-term anticholinergic therapy for prevention of recurrences in duodenal ulcer. Amer. J. dig. Dis., 9, 706-716.

Trevino, H., Anderson, J., Davey, P. G., and Henley, K. S. (1967) The effect of glycopyrrolate on the course of symptomatic duodenal ulcer. Amer. J. dig. Dis., 12, 983-987.

Watkinson, G. (1960). The incidence of chronic peptic ulcer found at necropsy: a study of 20,000 examinations performed in Leeds in 1930-49 and in England and Scotland in 1956. Gut, 1, 14-30. 